\title{
Tocilizumab Failed to Reduce Mortality in Severe COVID-19 Patients: Results From a Randomized Controlled Clinical Trial
}

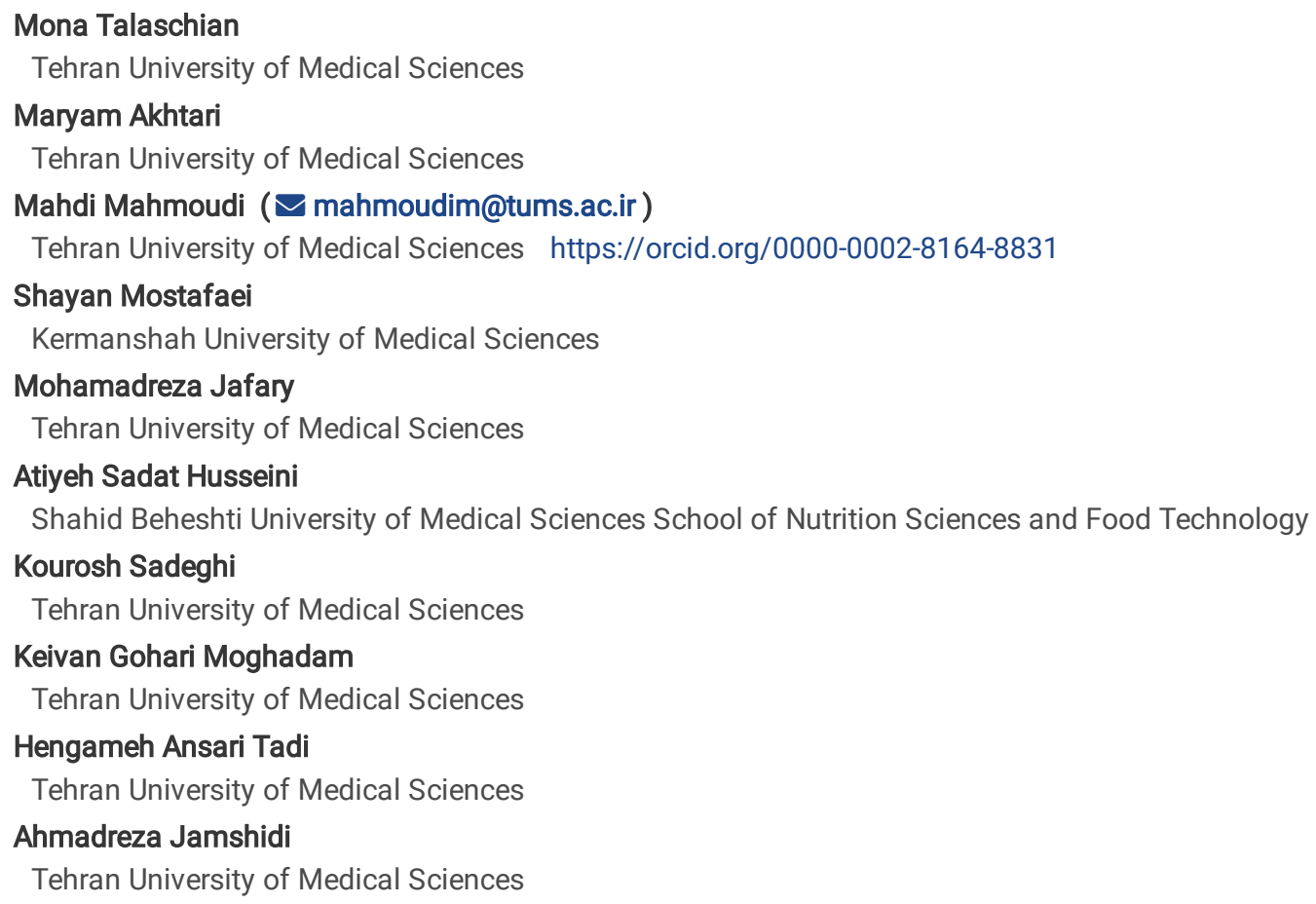

Research

Keywords: COVID-19, IL-6, Tocilizumab, RCT

Posted Date: May 6th, 2021

DOI: https://doi.org/10.21203/rs.3.rs-463921/v1

License: (c) (i) This work is licensed under a Creative Commons Attribution 4.0 International License. Read Full License 


\section{Abstract}

\section{Background}

Severe COVID-19 is associated with an increased level of blood IL-6. It is suggested that adjusting the IL-6 level or its effects may diminish the inflammation of the airway and alter the course of the disease.

\section{Methods}

We performed a controlled, randomized, double-blind clinical trial including severe hospitalized COVID-19 patients in Iran. The patients were randomly distributed by block randomization to take usual care plus IL-6 inhibitor (tocilizumab $8 \mathrm{mg} / \mathrm{kg}, 1$ or 2 dosages) or usual care alone (ratio $1: 1)$. The endpoint was defined by the clinical improvement and discharge or death. Main and safety analysis was performed in the overall population.

\section{Results}

We enrolled 40 eligible patients (20 patients in each group) from July 10 , till October 10, 2020, in this study. After randomization, one patient in the usual care arm and three patients in the tocilizumab arm refused to participate in the study and were eliminated from the study and overall analysis. The mean age of participants was $59.62 \pm 15.80$ and $63.52 \pm 12.83$ years old in Tocilizumab (8 women and 9 men) and standard care (9 women and 10 men) groups respectively ( $P$-value= 0.426$)$. The number of recovered patients did not significantly differ between tocilizumab and usual care groups $(70.6 \%(n=12)$ vs $78.9 \%(n=15)$ respectively) ( $P$-value=0.563). Also, the survival time was not significantly varied between participants in the tocilizumab intervention and usual care group [Log rank test: $P=0.973$; Hazard ratio: 1.25 ; $95 \%$ Cl: $0.249-4.209$ ].

\section{Conclusion}

The study results recommended that tocilizumab could not be a beneficial agent for treating severe cases of COVID-19 patients and have not significantly affected patients' clinical improvement.

\section{Clinical trial registration}

This trial was registered in the Iranian Registry of Clinical Trials on 9 July 2020 (ID: IRCT20081027001411N4) (https://www.irct.ir/trial/48396).

\section{Background}

Severe acute respiratory syndrome coronavirus (SARS-CoV)-2 that generates a pandemic of coronavirus disease 2019 (COVID-19) viral infection, has threatened human health and become a global concern since its emergence in late 2019 (1). COVID-19 presentations may range from light upper respiratory involvements to severe pneumonia that is characterized by immunological abnormalities, hyper-inflammation, and cytokine storm (2-4). Cytokine storm or excessive release of inflammatory cytokines leads to lethal organ damages, lung fibrosis, acute respiratory distress syndrome (ARDS), and even patients' death (5).

It has been demonstrated that the level of serum interleukin (IL)-10, II-8, IL-6, and tumor necrosis factor (TNF) was remarkably increased in severe or deceased patients compared to moderate or recovered cases $(1,6)$. IL-6 is a pro-inflammatory and pro-fibrotic cytokine that produce by immune cells including monocytes and lymphocytes as well as fibroblasts and bronchial epithelial cells and participates in the pathogenesis of lung fibrosis (7-9). It is found that IL-6 serum level in critically ill patients is almost 10 times more than in moderate cases (10). The elevated level of serum IL-6 is positively correlated with the SARS-CoV-2 RNAaemia (10), need for intubation (11), and disease severity stages of patients (12) and can be used as prognostic and diagnostic markers for COVID-19 severity. Therefore, it is suggested that administration of IL-6 signaling inhibitors might have efficient effects on the resolution of cytokine storm and treatment of individuals affected with COVID-19 who are in the pulmonary stage. Tocilizumab is a monoclonal antibody to the IL-6 receptor and is mainly used for the treatment of rheumatic disease (13). There are contradictory results regarding tocilizumab efficacy on COVID-19 patients (14-17). Therefore, in this randomized controlled trial (RCT), we investigated the effects of tocilizumab administration on the recovery, oxygen therapy, clinical and laboratory features of COVID-19 inpatients.

\section{Patients And Methods}

\subsection{Trail design}

This research is a double-blind, randomized, two-arm parallel, phase-2, controlled trial that was performed from July 10 till October $10,2020.40$ cases from Imam Khomeini and Shariati Hospital, Tehran University of Medical Sciences (TUMS) were included in this research. The trial protocol has been designed and mediated in adherence to the Consolidated Standards of Reporting Trials (CONSORT) guideline (18) and was approved by the Iranian Registry of Clinical Trials (ID: IRCT20081027001411N4). on 9 July 2020. According to the contradictory results about the effect of tocilizumab on COVID-19 patients, the lowest sample size with a 10\% drop-out rate was estimated 40 patients according to the effect size of 
tocilizumab on the pulmonary disease (19). The trial was conducted under the Declaration of Helsinki guidelines and was agreed by the Ethics Committee of the Tehran University of Medical Science (Approval Number: IR.TUMS.VCR.REC1399.290).

\subsection{Participants}

The confirmation of COVID-19 infection in patients was confirmed by the following specifications: 1. Confirmation of SARS-CoV-2 in nasopharyngeal swab via polymerase chain reaction (PCR) and 2. Atypical computed tomography (CT) features (subpleural, bilateral, peripheral ground-glass opacity). 18 years or older patients were eligible for enrollment in the trial if they complied with the following conditions: 1. Confirmed COVID-19 infection; 2. Elevated C-reactive protein (CRP higher than 10mg/L) or IL-6 (higher than 18 pg/ml) or lymphopenia (lymphocyte count under $1100 / \mathrm{MCL}$ ); 3 . At the pulmonary stage of the disease with blood oxygen saturation $<93 \%$ or respiratory rate (RR) higher than 24; 4 . Not connecting to the mechanical ventilator; 5 . Not responding to standard COVID-19 treatment. All participants provided informed consent before enrollment. Patients were not eligible for enrollment in the trial if they complied with the following conditions: 1 . Were allergic or intolerant to any therapeutic factors used in this study; 2 . With positive pro-calcitonin (PCT) and had an active infection (including latent or active tuberculosis (TB) infection); 3. Had a history of receiving immunosuppressive drugs and corticosteroids; 4 . With a history of active malignancies.

\subsection{Randomization and treatment}

Eligible patients (one or two days after hospitalization) were randomly distributed to the control and intervention groups by block randomization (1:1 ratio). One patient in the standard care arm and three patients in the tocilizumab arm refused to participate and were excluded from the study and overall analysis before baseline measurements. Patients allocated to receive usual care alone or usual care plus $8 \mathrm{mg} / \mathrm{kg}$ tocilizumab, (Actemra, Roche) (if the patient's conditions were not stable, 2 doses by 12 hours were administrated, maximum dose: 800 mg). All patients received usual care for the disease based on the Iranian protocol for diagnosis and treatment of COVID-19. The major standard medical cares that were received by COVID-19 patients are summarized in Table 1. In this study, patients, investigators, and outcome assessors did not inform which group received an intervention. Besides, a placebo was not used in the control group.

\subsection{Outcome}

The clinical, demographic, and laboratory data of the patients were recorded before their enrollment. Participants were followed through day 0 to 5 , improvement, discharge, or death. The primary outcome was improvement and discharge or death after administration of intervention whichever came first. The 28 days' mortality rate, time to improvement, and time to the event were also evaluated in each group.

Clinical characteristics of the patients such as RR, heart rate (HR), blood pressure, fever, and general symptoms including gastrointestinal involvement (GI), thorax pain, dyspnea, cough, weakness, and myalgia were assessed at enrollment and after 3-5 days of starting the treatment. Besides, the degree of oxygen saturation (SO2) and the necessity and type of oxygen supports including 1. Nasal cannula, 2. Simple oxygen mask, 3. Reservoir mask, 4. Noninvasive ventilation (NIV) and 5. Invasive ventilation were assessed at enrollment and after 3-5 days of starting the intervention. CT scan findings including pulmonary involvement percent and radiological properties were also evaluated at baseline and 6 weeks after treatment (only in participants who consented). Laboratory examinations to assess the level of complete blood count (CBC), alanine aminotransferase (ALT) and aspartate aminotransferase (AST) liver enzymes, CRP, erythrocyte sedimentation rate (ESR), fasting blood sugar (FBS), vein blood gas (VBG) (containing PH, the partial pressure of carbon dioxide (PCO2), and bicarbonate (HCO3)), IL-6, D-dimer, troponin, creatine phosphokinase (CPK) and ferritin were done at baseline and by 3-5 days of starting the treatment and also at hospital discharge time.

Improvement and discharge were determined by the patients' clinical, general, and laboratory conditions and were determined by consciousness, ameliorated dyspnea, stopped fever for 3 days, SO2 upper than 93\%, normal range of urinary output, tolerated oral regimen (PO), blood pressure more than 10 millimeters of mercury $(\mathrm{mm} \mathrm{Hg})$, a respiratory rate less than 20 breaths per minute, heart rate less than 90 beats per minutes, and reduced CRP amount and no any other side effects. All data were assessed during the study were registered on case report forms (CRFs) and the Excel database.

\subsection{Side events}

All unfavorable adverse effects experienced by participants during this trial, whether or not related to tocilizumab intervention, were assessed and stored.

\subsection{Statistical analysis}

All continuous variables were reported as the mean \pm standard deviation (SD) and categorical variables are expressed as $\mathrm{N}$ (\%). The Kolmogorov-Smirnov (K-S) normality test was used for continuous variables. Repeated measures ANOVA was performed for comparison between both groups over time. Besides, Mann Whitney or Student's t-tests was applied to assess the statistical contrasts between two arms in each time point. Moreover, Wilcoxon signed-rank or paired t-tests was performed to test for statistical comparison between two-time points in each of the studied intervention arms. Two-sided Chi-square/Fisher's exact tests were applied to test the associations between two intervention 
arms and the categorical variables. To analyze and draw the time-to-death curve between two intervention arms, Kaplan-Meier curve and the logrank test were applied. Using the Benjamini-Hochberg correction method for multiple comparisons, the false discovery rate was corrected. Statistical significance was defined at $\mathrm{p}<005$ and all statistical analysis was done by STATA software (Versions 11.2).

\section{Results}

\subsection{Patients}

Between July 10 to October 10, 2020, 40 eligible patients were randomly assigned to receive usual care plus tocilizumab ( $\mathrm{n}=20$ ), or usual care alone $(n=20)$. One patient in the standard care arm and 3 patients in the tocilizumab arm refused to participate in the trial and were excluded from the study and overall analysis. The results for the outcomes were not significantly distinct from the results of intention to treat (ITT), according to the analysis per protocol. The patients' enrollment, randomization, and assignment are summarized in Figure 1. The mean age of participants was $61.74 \pm 14.19$ years old $(19$ (52.8\%) men and 17 (47.2\%) women). There are no notable differences between the two arms regarding their sex and age ( $P=0.99$ and $P=0.426$ respectively). In the tocilizumab group, 12 patients $(70.6 \%)$ received one dose and 5 patients ( $29.4 \%)$ received two doses of tocilizumab. The coexisting conditions and clinical characteristics of patients at enrolment were shown in Table 1. Nine patients (25\%) had RR upper than 24 breaths per minute and 14 patients (38.9\%) had an HR of more than 100 beats per minute. Dyspnea, weakness, and cough were the most prevalent symptoms in patients. Except for RR which was higher in patients of the tocilizumab arm, there were no substantial between-group differences in clinical features, comorbidity conditions, and administrated standard medical care at enrollment. Besides, except for ALT which was significantly elevated in the tocilizumab group, and ESR which was notably elevated in the usual care group, we did not observe significant between-group differences regarding laboratory features at enrolment.

The average blood SO2 level was $84.6 \pm 8.92$ at baseline. All of the patients had peripheral ground-glass opacity at enrollment and the majority of them had $10-30 \%(38.8 \%)$ and $30-50 \%(27.7 \%)$ respiratory involvements respectively. All participants were receiving oxygen supports at baseline and the majority of them (80\%) were received nasal cannula. Pulmonary involvement level and CT scan findings of patients in each group at baseline were summarized in Table 2.

\subsection{Primary outcome}

Mortality at 28 days was not considerably different between patients in the tocilizumab arm and standard care, with death reported in 5 (29.4\%) and 4 (21.1\%) patients respectively (Table 3). performing Kaplan-Meier estimator of time to death (day), we showed that the survival time was not significantly varied between patients in the tocilizumab intervention arm and usual care arm [Log rank test: $P=0.973 ;$ Hazard ratio: 1.25 ; $95 \%$ Cl: 0.249-4.209] (Figure 2).

We also did not observe a major difference in the time to event (improvement, or death) between participants assigned to the tocilizumab and standard care arms (median, $12.88 \pm 9.05$ days vs $12.05 \pm 8.92$ days; $P=0.784$ ). Also, the time to improvement was not considerably different between the two arms (median, $9.42 \pm 3.55$ days in the tocilizumab group vs $9.73 \pm 6.05$ days in the usual care group; $P=0.874$ ) (Table 3 ).

The number of patients in each oxygen support group at baseline and after 3-5 days of starting the treatment and the primary outcomes of them in both standard care and tocilizumab arms were shown in Supplementary Figure 1. We did not observe notable differences in the incidence of death according to the type of oxygen therapy in patients. Of the dead patients, 55.5\% (2 patients in the control arm and 3 patients in the tocilizumab arm) had pulmonary involvement percent more than $70 \%$, and $22 \%$ had pulmonary involvement percent between 50 to $70 \%$ (one patient in each group).

\subsection{Secondary outcome}

The level of participants' blood SO2 was substantially ameliorated by $3-5$ days of treatment in both groups $(P=0.001$ and $P=0.002$ in the tocilizumab and standard care respectively). Although the body temperature was reduced in both groups after 3-5 days of treatment, the reduction was only significant in patients in the usual care arm. We did not observe significant differences in the blood pressure HR and RR before and after 3-5 days of treatment in patients of both arms. After 3-5 days of starting the treatment, the number of patients suffered from dyspnea was significantly reduced in both the tocilizumab and standard care treatment group $(P=0.012$ and $P=0.031$ respectively). However, we did not observe significant beneficial effects of tocilizumab on the reduction of $\mathrm{GI}$ symptoms, myalgia, and cough in patients, and the symptoms only were significantly improved in the usual care arm. Clinical features of participants before and after treatment were summarized in Table 4.

4 of 17 patients in the tocilizumab arm and 2 of 19 patients in the standard care arm did not need oxygen supplement by $3-5$ days of treatment. The oxygen support status was improved in 7 of 17 patients (41.1\%) in the tocilizumab arm and 3 of 19 patients in the control arm (15.7\%) (Figure S1).

\subsection{Laboratory findings}


The hemoglobin level was notably reduced in the control group of patients by 3-5 days of starting the treatment and also at discharge time ( $P=0.002$ and $P=0.025$ respectively). Besides, the hematocrit percentage was diminished in patients who received standard care treatment at discharge time. While the level of hemoglobin and hematocrit percentage did not change in patients of the tocilizumab group. Tocilizumab also reduced neutrophil percentage in patients, nevertheless, we did not detect a significant reduction in the percentage of neutrophil in patients who received standard care. Besides, although tocilizumab reduced IL-6 level, the reduction was not significant. Except for hemoglobin and hematocrit levels, we did not detect any significant differences in the level of laboratory characteristics of patients during treatment in either group (Table 5).

\subsection{Safety}

Although we did not see serious adverse events in the usual care arm, a total of three patients (17.6\%) in the tocilizumab arm showed serious side events between initiation of intervention and the end of the trial. Shock and infection developed in three and one patient in the tocilizumab arm respectively. Of these four adverse events, 3 were considered to be related or possibly related and one was considered to be unrelated to intervention by the site investigators. All serious adverse events are shown in Supplementary Table 1.

\section{Discussion}

It has been found that the level of serum IL- 6 is elevated in critically ill COVID-19 patients and it is correlated with the severity of illness in patients $(1,6,12)$. It is suggested that administration of IL-6 receptor inhibitor might prevent the progression of cytokine storm in COVID-19 patients who are in the pulmonary stage. Therefore, we aimed to investigate the effects of tocilizumab administration as an IL-6 receptor blockage, on the treatment and clinical and laboratory characteristics of hospitalized COVID-19 patients. We did not find beneficial effects for the administration of tocilizumab in the treatment of severe COVID-19 patients in our RCT. Although tocilizumab administration improved the oxygen support status of more patients in the intervention arm compared to the control arm by 3-5 days of treatment, it could not improve the survival time, reduce the mortality rate and decrease the time to discharge in the intervention group. Except for the significant effects of tocilizumab treatment on the maintenance of hemoglobin level and the reduction of neutrophil percent in patients, we did not find any therapeutic effects of tocilizumab on the improvement of clinical and laboratory characteristics of patients. Same as our results, previously the effect of tocilizumab on the improvement of anemia and reduction of the neutrophil count has been shown in rheumatoid arthritis (RA) patients $(20,21)$.

Some observational and cohort studies investigated the effect of tocilizumab on COVID-19 patients and reported contradictory results regarding its treatment efficacy (14-17). In a case-control study by Marte et al., on severe to critical COVID-19 patients who received tocilizumab, no difference in mortality rate has been found in all studied patients. However, they found that the treatment can reduce the mortality rate in nonintubated patients (14). PharmD et al., in an observational study, reported limited improvement effects for tocilizumab. In their study, from patients who received tocilizumab, $42 \%$ were expired and $49 \%$ were improved (17).

In contrast to our results, Rossotti et al. found tocilizumab as potentially effective care for COVID-19 patients which was associated with improved overall survival in patients compared to controls.(15) Moreover, results from an observational cohort research on patients with severe COVID-19 pneumonia showed that intravenous or subcutaneous tocilizumab may reduce the risk of mortality and the risk of intubation in patients (22). Xu et al. also prospectively observed tocilizumab effects on treating COVID-19 patients. They found that tocilizumab improved clinical outcomes including fever, oxygen intake, lymphocytes percentage, and CRP level immediately in patients (23). Besides, in a Cohort study by Somers et al., tocilizumab administration was associated with reduced mortality rate and increased reinfection occurrence in intubated COVID19 patients (24). Moreover, according to the observational study by Jordan et al., tocilizumab might offer beneficial effects in reducing COVID-19 associated mortality, inflammation, and oxygen supports in patients (25).

Although there are several observational studies regarding the use of tocilizumab on the treatment of COVID-19 affected individuals, some randomized controlled clinical trials are required to determine the exact effect of treatment. Except for this study, there are other clinical trials regarding the effect of tocilizumab on COVID-19. In the RECOVERY trial by Horby et al., the effect of intravenously 400 mg to 800 mg tocilizumab was evaluated on 4116 hospitalized COVID-19 patients with systemic inflammation. In contrast to our results, they reported that tocilizumab treatment improved clinical characteristics and survival outcomes in patients. Patients who received tocilizumab had an increased chance of discharged from the hospital alive and a reduced chance of progressing to require intubation or death (26). In another clinical trial by Stone et al., the effect of tocilizumab administration was assessed on 243 moderately ill hospitalized COVID-19 patients at hyperinflammatory states who were not intubated. In line with our results, they did not find tocilizumab an effective treatment for preventing death or mechanical invasive ventilation in patients (27). in compliance with our study, Veiga et al. conducted a clinical trial on 129 COVID-19 patients who received support oxygen or mechanical ventilation. They also did not observe a superior effect for tocilizumab compared to standard care in improving clinical features. Besides, their result showed that tocilizumab may increase the mortality rate in patients (28).

Our study also has some limitations and weaknesses such as the possible existed bias, lack of placebo, and low sample size. Therefore, to determine the exact therapeutic effect of tocilizumab on COVID-19 patients, more clinical trials on COVID-19 patients on different disease stages are needed. 


\section{Conclusions}

Our results in this randomized, controlled, double-blind clinical trial showed no significant effect for tocilizumab intervention on the treatment of non-intubated, severe COVID-19 patients who had elevated IL-6 levels. Tocilizumab treatment did not significantly change recovery rate, survival time, and time to event in affected individuals. Regarding the positive effects of corticosteroids administration on COVID-19 patients(29, 30), it seems that using systemic immunosuppression or a combination of various therapeutic agents might be more efficient than blocking a specific cytokine pathway.

\section{Abbreviation List}

ALT: Alanine aminotransferase; ARDS: Acute respiratory distress syndrome; AST: Aspartate aminotransferase; CBC: Complete blood count; CONSORT: Consolidated Standards of Reporting Trials; COVID-19: Coronavirus disease 2019; CPK: Creatine phosphokinase; CRF: Case report form; CRP: C-reactive protein; CT: Computed tomography; ESR: Erythrocyte sedimentation rate; FBS: Fasting blood sugar; GI: Gastrointestinal involvement; HCO3: Bicarbonate; HR: Heart rate; IL: Interleukin; ITT: Intention to treat; mmHg: Millimeters of mercury; NIV: Noninvasive ventilation; PCO2: Partial pressure of carbon dioxide; PCT: Pro-calcitonin; PO: Tolerated oral regimen; RA: Rheumatoid arthritis; RCT: Randomized controlled trial; RR: Respiratory rate; SARS-CoV-2: Severe acute respiratory syndrome coronavirus 2; SD: Standard deviation; SO2: Oxygen saturation; TB: Tuberculosis; TNF: Tumor necrosis factor; VBG: Vein blood gas.

\section{Declarations}

\section{Ethics approval}

This study was performed based on the Declaration of Helsinki guidelines and was approved by the ethics committee at the Tehran University of Medical Sciences (Approval ID: IR.TUMS.VCR.REC1399.290).

\section{Consent to participate}

The written informed consent was signed by all patients before enrolling in the study.

\section{Availability of data and materials}

Data are available upon reasonable request.

\section{Competing interests}

The authors declare that they have no conflicts of interest.

\section{Funding}

This study was supported by a grant from the Deputy of Research, Tehran University of Medical Sciences (Grant No. 99-1-96-47101).

\section{Role of the funding source}

The funder of the study had no role in study design, data collection, data analysis, data interpretation, or writing of the report. The corresponding author had full access to all the data in the study and had final responsibility for the decision to submit it for publication.

\section{Authors' contributions}

MT, MJ, ASH, KS, KGM, HAT: Acquisition of clinical data and patient's diagnosis and treatment, interpretation of data, drafting the article, and final approval of the article.

MA, MM, SM, and AJ: The conception and design of the study, analysis and interpretation of data, revising the article critically for important intellectual content, and final approval of the article.

\section{Acknowledgments}

None.

\section{References}

1. Chen G, Wu D, Guo W, Cao Y, Huang D, Wang H, et al. Clinical and immunological features of severe and moderate coronavirus disease 2019. J Clin Invest. 2020;130:2620-9. 
2. Huang C, Wang Y, Li X, Ren L, Zhao J, Hu Y, et al. Clinical features of patients infected with 2019 novel coronavirus in Wuhan, China. Lancet. 2020;395:497-506.

3. Guan WJ, Ni ZY, Hu Y, Liang WH, Ou CQ, He JX, et al. Clinical Characteristics of Coronavirus Disease 2019 in China. N Engl J Med. 2020;382:1708-20.

4. Richardson S, Hirsch JS, Narasimhan M, Crawford JM, McGinn T, Davidson KW, et al. Presenting Characteristics, Comorbidities, and Outcomes Among 5700 Patients Hospitalized With COVID-19 in the New York City Area. Jama. 2020;323:2052-9.

5. Castelli V, Cimini A and Ferri C. Cytokine Storm in COVID-19: "When You Come Out of the Storm, You Won't Be the Same Person Who Walked in". Frontiers in immunology. 2020;11:2132-

6. Chen T, Wu D, Chen H, Yan W, Yang D, Chen G, et al. Clinical characteristics of 113 deceased patients with coronavirus disease 2019: retrospective study. BMJ. 2020;368:m1091.

7. Yoshikawa T, Hill T, Li K, Peters CJ, Tseng CT. Severe acute respiratory syndrome (SARS) coronavirus-induced lung epithelial cytokines exacerbate SARS pathogenesis by modulating intrinsic functions of monocyte-derived macrophages and dendritic cells. J Virol. 2009;83:3039-48.

8. Saito F, Tasaka S, Inoue K-i, Miyamoto K, Nakano Y, Ogawa Y, et al. Role of Interleukin-6 in Bleomycin-Induced Lung Inflammatory Changes in Mice. American Journal of Respiratory Cell and Molecular Biology. 2008;38:566-71.

9. O'Donoghue RJJ, Knight DA, Richards CD, Prêle CM, Lau HL, Jarnicki AG, et al. Genetic partitioning of interleukin-6 signalling in mice dissociates Stat3 from Smad3-mediated lung fibrosis. EMBO Molecular Medicine. 2012;4:939-51.

10. Chen X, Zhao B, Qu Y, Chen Y, Xiong J, Feng Y, et al. Detectable Serum Severe Acute Respiratory Syndrome Coronavirus 2 Viral Load (RNAemia) Is Closely Correlated With Drastically Elevated Interleukin 6 Level in Critically III Patients With Coronavirus Disease 2019. Clinical infectious diseases : an official publication of the Infectious Diseases Society of America. 2020;71:1937-42.

11. Herold T, Jurinovic V, Arnreich C, Lipworth BJ, Hellmuth JC, von Bergwelt-Baildon M, et al. Elevated levels of IL-6 and CRP predict the need for mechanical ventilation in COVID-19. J Allergy Clin Immunol. 2020;146:128-36.e4.

12. Zhang J, Hao Y, Ou W, Ming F, Liang G, Qian Y, et al. Serum interleukin-6 is an indicator for severity in 901 patients with SARS-CoV-2 infection: a cohort study. Journal of Translational Medicine. 2020;18:406.

13. Venkiteshwaran A. Tocilizumab. MAbs. 2009;1:432-8.

14. Rojas-Marte G, Khalid M, Mukhtar O, Hashmi AT, Waheed MA, Ehrlich S, et al. Outcomes in patients with severe COVID-19 disease treated with tocilizumab: a case-controlled study. Qjm. 2020;113:546-50.

15. Rossotti R, Travi G, Ughi N, Corradin M, Baiguera C, Fumagalli R, et al. Safety and efficacy of anti-il6-receptor tocilizumab use in severe and critical patients affected by coronavirus disease 2019: A comparative analysis. The Journal of infection. 2020;81:e11-e7.

16. Xu X, Han M, Li T, Sun W, Wang D, Fu B, et al. Effective treatment of severe COVID-19 patients with tocilizumab. Proc Natl Acad Sci U S A. 2020;117:10970-5.

17. Knorr JP, Colomy V, Mauriello CM, Ha S. Tocilizumab in patients with severe COVID-19: A single-center observational analysis. Journal of Medical Virology. 2020;92:2813-20.

18. Moher D, Hopewell S, Schulz KF, Montori V, Gotzsche PC, Devereaux PJ, et al. CONSORT 2010 explanation and elaboration: updated guidelines for reporting parallel group randomised trials. BMJ. 2010;340:c869.

19. Hernández-Sánchez J, Harlow L, Church C, Gaine S, Knightbridge E, Bunclark K, et al. Clinical trial protocol for TRANSFORM-UK: A therapeutic open-label study of tocilizumab in the treatment of pulmonary arterial hypertension. Pulm Circ. 2018;8:2045893217735820.

20. Moots RJ, Sebba A, Rigby W, Ostor A, Porter-Brown B, Donaldson F, et al. Effect of tocilizumab on neutrophils in adult patients with rheumatoid arthritis: pooled analysis of data from phase 3 and 4 clinical trials. Rheumatology (Oxford, England). 2017;56:541-9.

21. Hashimoto M, Fujii T, Hamaguchi M, Furu M, Ito H, Terao C, et al. Increase of hemoglobin levels by anti-IL-6 receptor antibody (tocilizumab) in rheumatoid arthritis. PLoS One. 2014;9:e98202.

22. Guaraldi G, Meschiari M, Cozzi-Lepri A, Milic J, Tonelli R, Menozzi M, et al. Tocilizumab in patients with severe COVID-19: a retrospective cohort study. Lancet Rheumatol. 2020;2:e474-e84.

23. Xu X, Han M, Li T, Sun W, Wang D, Fu B, et al. Effective treatment of severe COVID-19 patients with tocilizumab. Proceedings of the National Academy of Sciences of the United States of America. 2020;117:10970-5.

24. Somers EC, Eschenauer GA, Troost JP, Golob JL, Gandhi TN, Wang L, et al. Tocilizumab for Treatment of Mechanically Ventilated Patients With COVID-19. Clinical Infectious Diseases. 2020.

25. Jordan SC, Zakowski P, Tran HP, Smith EA, Gaultier C, Marks G, et al. Compassionate Use of Tocilizumab for Treatment of SARS-CoV-2 Pneumonia. Clinical Infectious Diseases. 2020;71:3168-73.

26. Horby PW, Pessoa-Amorim G, Peto L, Brightling CE, Sarkar R, Thomas K, et al. Tocilizumab in patients admitted to hospital with COVID-19 (RECOVERY): preliminary results of a randomised, controlled, open-label, platform trial. medRxiv. 2021:2021.02.11.21249258.

Page $7 / 15$ 
27. Stone JH, Frigault MJ, Serling-Boyd NJ, Fernandes AD, Harvey L, Foulkes AS, et al. Efficacy of Tocilizumab in Patients Hospitalized with Covid-19. New England Journal of Medicine. 2020;383:2333-44.

28. Veiga VC, Prats JAGG, Farias DLC, Rosa RG, Dourado LK, Zampieri FG, et al. Effect of tocilizumab on clinical outcomes at 15 days in patients with severe or critical coronavirus disease 2019: randomised controlled trial. BMJ. 2021;372:n84.

29. Edalatifard M, Akhtari M, Salehi M, Naderi Z, Jamshidi A, Mostafaei S, et al. Intravenous methylprednisolone pulse as a treatment for hospitalised severe COVID-19 patients: results from a randomised controlled clinical trial. Eur Respir J. 2020;56.

30. Dexamethasone in Hospitalized Patients with Covid-19. New England Journal of Medicine. 2020;384:693-704.

\section{Tables}

Table 1: Demographic and clinical characteristics of the patients at baseline. 


\begin{tabular}{|c|c|c|c|c|c|}
\hline & Characteristic & $\begin{array}{l}\text { Total } \\
(\mathrm{N}=36)\end{array}$ & $\begin{array}{l}\text { Tocilizumab } \\
(\mathrm{N}=17)\end{array}$ & $\begin{array}{l}\text { Standard care } \\
(\mathrm{N}=19)\end{array}$ & $\begin{array}{l}P \\
\text { value }\end{array}$ \\
\hline & Age (years) & $61.74 \pm 14.19$ & $59.62 \pm 15.80$ & $63.52 \pm 12.83$ & 0.426 \\
\hline & Male/female, No (\%) & $\begin{array}{l}19 / 17 \\
(52.77 \%)\end{array}$ & $9 / 8(52.9 \%)$ & $10 / 9(52.6 \%)$ & 0.99 \\
\hline & BMI & $28.28 \pm 4.25$ & $29.08 \pm 3.32$ & $27.53 \pm 4.96$ & 0.29 \\
\hline & Tocilizumab Doses 0 & $19(52.8 \%)$ & - & $19(100 \%)$ & \multirow[t]{3}{*}{ NA } \\
\hline & Tocilizumab Doses 1 & $12(33.3 \%)$ & $12(70.6 \%)$ & - & \\
\hline & Tocilizumab Doses 2 & $5(13.9 \%)$ & $5(29.4 \%)$ & - & \\
\hline & Crowded places, n/N (\%) & $24 / 29(82.7 \%)$ & $12 / 13(92.3 \%)$ & $12 / 16(75 \%)$ & 0.343 \\
\hline \multirow[t]{9}{*}{ Coexisting conditions } & Diabetes, $\mathrm{n} / \mathrm{N}(\%)$ & $13 / 36(36.1 \%)$ & $8 / 17(47 \%)$ & $5 / 19(26.3 \%)$ & 0.196 \\
\hline & Hypothyroidism, n/N (\%) & $5 / 36(13.9 \%)$ & $3 / 17(17.6 \%)$ & $2 / 19(10.5 \%)$ & 0.650 \\
\hline & Respiratory disorder, n/N (\%) & $3 / 36(8.3 \%)$ & $1 / 17(5.9 \%)$ & $2 / 19(10.5 \%)$ & 0.99 \\
\hline & Renal disorder, $\mathrm{n} / \mathrm{N}$ (\%) & $1 / 36(2.8 \%)$ & 0 & $1 / 19(5.3 \%)$ & 0.99 \\
\hline & Cardiovascular disorder, $\mathrm{n} / \mathrm{N}$ (\%) & $16 / 36(44.4 \%)$ & $7 / 17(41.1 \%)$ & 9/19 (47.3\%) & 0.709 \\
\hline & Hypertension, n/N (\%) & $18 / 36(50 \%)$ & $9 / 17(52.9 \%)$ & 9/19 (47.3\%) & 0.738 \\
\hline & $\mathrm{GI}, \mathrm{n} / \mathrm{N}(\%)$ & $3 / 36(8.3 \%)$ & $1 / 17(5.9 \%)$ & $2 / 19(10.5 \%)$ & 0.99 \\
\hline & Cancer, n/N (\%) & 0 & 0 & 0 & NA \\
\hline & $\begin{array}{l}\text { Autoimmune \& neurodegenerative diseases, } \mathrm{n} / \mathrm{N} \\
\text { (\%) }\end{array}$ & 0 & 0 & 0 & NA \\
\hline \multirow{19}{*}{$\begin{array}{l}\text { Other COVID-19 } \\
\text { treatment }\end{array}$} & Hydroxy Chloroquine, n/N (\%) & $23 / 36(63.9 \%)$ & $9 / 17(52.9 \%)$ & $14 / 19(73.3 \%)$ & 0.196 \\
\hline & Atazanavir, n/N (\%) & $5 / 35(13.9 \%)$ & $3 / 17(17.6 \%)$ & $2 / 19(10.5 \%)$ & 0.65 \\
\hline & Corticosteroids, $\mathrm{n} / \mathrm{N}(\%)$ & $12 / 36(33.3 \%)$ & $5 / 17(29.4 \%)$ & $7 / 19(36.8 \%)$ & 0.637 \\
\hline & Interferon, n/N (\%) & $1 / 36(2.8 \%)$ & $1 / 17(5.9 \%)$ & 0 & 0.472 \\
\hline & Lopinavir / Ritonavir, n/N (\%) & $3 / 36(8.3 \%)$ & $3 / 17(17.6 \%)$ & 0 & 0.095 \\
\hline & Body temperature, ${ }^{\circ} \mathrm{C}, \mathrm{n} / \mathrm{N}(\%)$ & $37.29 \pm 1.14$ & $37.02 \pm 1.50$ & $37.51 \pm 0.73$ & 0.216 \\
\hline & Respiratory rate, breaths/ min & $20.25 \pm 3.50$ & $21.76 \pm 3.81$ & $18.89 \pm 2.60$ & $0.015^{\star}$ \\
\hline & Respiratory rate $>24$ breaths/min, , $\mathrm{n} / \mathrm{N}$ (\%) & $9 / 36(25 \%)$ & $7 / 17(41.1 \%)$ & $2 / 19(10.5 \%)$ & 0.055 \\
\hline & Heart Rate, beats/min & $91.94 \pm 14.42$ & $90.76 \pm 14.92$ & $93.0 \pm 14.28$ & 0.649 \\
\hline & Heart Rate >100 beats/min, , n/N (\%) & $14 / 36(38.9 \%)$ & $5 / 17(29.4 \%)$ & 9/19 (47.3\%) & 0.27 \\
\hline & Systolic blood pressure, mm Hg & $127.75 \pm 24.95$ & $122.76 \pm 24.77$ & $132.21 \pm 24.92$ & 0.263 \\
\hline & Diastolic blood pressure, $\mathrm{mm} \mathrm{Hg}$ & $74.05 \pm 16.59$ & $68.81 \pm 17.37$ & $78.47 \pm 14.95$ & 0.086 \\
\hline & Dyspnea, $\mathrm{n} / \mathrm{N}(\%)$ & $31 / 36(86.1 \%)$ & $\begin{array}{l}15 / 17 \\
(88.23 \%)\end{array}$ & $16 / 19(84.2 \%)$ & 0.99 \\
\hline & GI Symptom, n/N (\%) & $12 / 36(33.3 \%)$ & $5 / 17(29.4 \%)$ & $7 / 19(36.8 \%)$ & 0.637 \\
\hline & Myalgia, n/N (\%) & $15 / 36(41.7 \%)$ & $5 / 17(29.4 \%)$ & $10 / 19(52.6 \%)$ & 0.158 \\
\hline & Chest pain, $\mathrm{n} / \mathrm{N}(\%)$ & $5 / 36(13.9 \%)$ & $3 / 17(17.6 \%)$ & $2 / 19(10.5 \%)$ & 0.65 \\
\hline & Cough, n/N (\%) & $21 / 36(58.3 \%)$ & $9 / 17(52.9 \%)$ & $12 / 19(63.1 \%)$ & 0.535 \\
\hline & Weakness, n/N (\%) & $31 / 36(86.1 \%)$ & $14 / 17(82.4 \%)$ & $17 / 19(89.5 \%)$ & 0.65 \\
\hline & WBC count/MCL & $6995 \pm 2699$ & $7668 \pm 2808$ & $6428 \pm 2539$ & 0.179 \\
\hline \multirow[t]{2}{*}{ WBC count } & 4-10 ×1000/MCL, no (\%) & $29 / 35(82.9 \%)$ & $13 / 16(81.2 \%)$ & $16 / 19(84.2 \%)$ & \multirow[t]{2}{*}{0.99} \\
\hline & $<4 \times 10 \times 1000 / \mathrm{MCL}, \mathrm{no}(\%)$ & $4 / 35(11.4 \%)$ & $2 / 16(12.5 \%)$ & $2 / 19(10.5 \%)$ & \\
\hline
\end{tabular}




\begin{tabular}{|c|c|c|c|c|c|}
\hline & >10 ×1000/MCL, no (\%) & $2 / 35(5.7 \%)$ & $1 / 16(6.3 \%)$ & 1/19 (5.3\%) & \\
\hline & RBC count $(\times 1000) / M C L$ & $4.42 \pm 0.932$ & $4.43 \pm 1.21$ & $4.42 \pm 0.639$ & 0.984 \\
\hline & Lymphocyte count/MCL & $1079 \pm 561$ & $1212 \pm 634$ & $910 \pm 421$ & 0.188 \\
\hline \multirow[t]{5}{*}{ Lymphocyte count } & 800-5000/MCL, n/N (\%) & $14 / 25(56 \%)$ & $10 / 14(71.4 \%)$ & 4/11 (36.4\%) & \multirow[t]{3}{*}{0.116} \\
\hline & <800/MCL, n/N (\%) & $11 / 25(44 \%)$ & 4/14 (28.6\%) & 7/11 (63.6\%) & \\
\hline & >5000/MCL, n/N (\%) & 0 & 0 & 0 & \\
\hline & Monocyte count/MCL & $380.6 \pm 224.9$ & $395.8 \pm 281.9$ & $359.4 \pm 116.5$ & 0.704 \\
\hline & Platelet count/MCL & $\begin{array}{l}200971 \pm \\
70615\end{array}$ & $\begin{array}{l}196625 \pm \\
70727\end{array}$ & $\begin{array}{l}204631 \pm \\
72246\end{array}$ & 0.744 \\
\hline \multirow[t]{6}{*}{ Platelet count } & $<150 \times 1000 / M C L, n / N(\%)$ & 6/35 (17.1\%) & 2/16 (12.5\%) & 4/19 (21.1\%) & \multirow[t]{3}{*}{0.666} \\
\hline & 150-450×1000/MCL, n/N (\%) & 29/35 (82.9\%) & $14 / 16(87.5 \%)$ & 15/19 (78.9\%) & \\
\hline & >450×1000/MCL, n/N (\%) & 0 & 0 & 0 & \\
\hline & Neutrophil Percent (\%) & $76.24 \pm 9.33$ & $75.85 \pm 9.98$ & $76.27 \pm 8.90$ & 0.823 \\
\hline & Hemoglobin (gm/dl) & $12.38 \pm 2.45$ & $11.89 \pm 3.13$ & $12.78 \pm 1.66$ & 0.288 \\
\hline & Hematocrit (\%) & $36.44 \pm 6.30$ & $35.44 \pm 7.26$ & $37.39 \pm 5.30$ & 0.383 \\
\hline \multirow[t]{15}{*}{ VBG } & PCO2 (mmHg) & $41.06 \pm 8.77$ & $40.06 \pm 7.60$ & $41.88 \pm 9.78$ & 0.561 \\
\hline & $\mathrm{HCO} 3$ (meq/L) & $24.74 \pm 5.11$ & $23.20 \pm 5.42$ & $26.10 \pm 4.56$ & 0.111 \\
\hline & PH & $7.38 \pm 0.107$ & $7.36 \pm 0.152$ & $7.40 \pm 0.047$ & 0.224 \\
\hline & ALT (U/L) & $37.65 \pm 26.43$ & $50.92 \pm 34.74$ & $27.33 \pm 9.64$ & $0.027 *$ \\
\hline & AST (U/L) & $47.81 \pm 18.02$ & $52.64 \pm 21.13$ & $44.05 \pm 14.71$ & 0.186 \\
\hline & CPK (U/L) & $160.3 \pm 161.7$ & $148.3 \pm 89.9$ & $167.5 \pm 195.4$ & 0.785 \\
\hline & FBS mg/dL & $135.1 \pm 53$ & $139 \pm 53.47$ & $132.1 \pm 54.31$ & 0.745 \\
\hline & CRP (mg/L) & $67.76 \pm 40.10$ & $71.78 \pm 49.45$ & $64.58 \pm 31.98$ & 0.611 \\
\hline & ESR (mm/hr) & $56.75 \pm 33.47$ & $42.93 \pm 28.06$ & $68.27 \pm 33.93$ & $0.028^{*}$ \\
\hline & Ferritin (ng/mL) & $507 \pm 469$ & $601.8 \pm 653.7$ & $433.3 \pm 250.7$ & 0.374 \\
\hline & IL-6 (pg/ml) & $437.3 \pm 619$ & $622.9 \pm 741.9$ & $271.3 \pm 440.4$ & 0.471 \\
\hline & D-Dimer $(\mu \mathrm{g} / \mathrm{mL})$ & $0.895 \pm 0.963$ & $0.69 \pm 0.292$ & $1.05 \pm 1.25$ & 0.784 \\
\hline & Troponin pg/mL & $22.92 \pm 55.71$ & $31.73 \pm 79.72$ & $15.20 \pm 18.87$ & 0.759 \\
\hline & SARS-CoV-2 PCR positive, n/N (\%) & $36 / 36(100 \%)$ & $17 / 17(100 \%)$ & 19/19 (100\%) & NA \\
\hline & Pro-calcitonin negative, n/N (\%) & $36 / 36(100 \%)$ & $17 / 17(100 \%)$ & 19/19 (100\%) & NA \\
\hline
\end{tabular}

ALT: Alanine aminotransferase; AST: Aspartate aminotransferase; BMI: Body mass index; ${ }^{\circ} \mathrm{C}$ : Centigrade; CPK: Creatine phosphokinase; CRP: Creactive protein; ESR: erythrocyte sedimentation rate; FBS: Fasting blood sugar; Gl: Gastrointestinal; gm/dl: Grams per deciliter; HCO3:

Bicarbonate; LDH: Lactic acid dehydrogenase; MCL: Microliter; $\mu \mathrm{g} / \mathrm{mL}$ : Microgram per milliliter; $\mathrm{mg} / \mathrm{L}$ : Milligrams per liter; meq/L: Milliequivalent per liter; min: Minute; mm Hg: Millimeter of mercury; mm/hr: Millimeters per hour; ng/ml: Nanogram per milliliter; PCO2: Partial pressure of carbon dioxide; pg/ml: Pictogram per milliliter; RBC: Red blood cell; U/L: Unit per liter; VBG: Venous blood gas; WBC: White blood cell; NA: Not available; $\star P$-value $<0.05$.

Table 2. Pulmonary involvement level at baseline. 


\begin{tabular}{|c|c|c|c|c|c|}
\hline & Characteristic & $\begin{array}{l}\text { Total } \\
(\mathrm{N}=36)\end{array}$ & $\begin{array}{l}\text { Tocilizumab } \\
(\mathrm{N}=17)\end{array}$ & $\begin{array}{l}\text { Standard care } \\
(\mathrm{N}=19)\end{array}$ & $P$-value \\
\hline & SO2 percent & $84.6 \pm 8.92$ & $84.8 \pm 8.21$ & $84.4 \pm 9.73$ & 0.881 \\
\hline & Need on oxygen therapy, n/N (\%) & $36 / 36(100 \%)$ & $17 / 17(100 \%)$ & $19 / 19(100 \%)$ & NA \\
\hline \multirow[t]{4}{*}{ Type of oxygen therapy, no (\%) } & Nasal Cannula & $18 / 36(80 \%)$ & $8 / 17(47.1 \%)$ & $10 / 19(52.6 \%)$ & \multirow[t]{4}{*}{0.106} \\
\hline & Simple Mask & $11 / 36(30.6 \%)$ & $3 / 17(17.6 \%)$ & $8 / 19(42.1 \%)$ & \\
\hline & Reservoir Mask & $4 / 36(11.1 \%)$ & $3 / 17(17.6 \%)$ & $1 / 19(5.3 \%)$ & \\
\hline & Noninvasive ventilation (NIV) & $3 / 36(8.3 \%)$ & $3 / 17(17.6 \%)$ & 0 & \\
\hline \multirow[t]{5}{*}{ Pulmonary involvement percent, $n / N(\%)$} & $A(<10 \%)$ & $4 / 36(11.1 \%)$ & $1 / 17(5.8 \%)$ & $3 / 19(15.8 \%)$ & \multirow[t]{5}{*}{0.788} \\
\hline & B (10-30\%) & $14 / 36(38.8 \%)$ & $6 / 17(35.3 \%)$ & $8 / 19(42.1 \%)$ & \\
\hline & $C(30-50 \%)$ & $10 / 36(27.7 \%)$ & $5 / 17(29.4 \%)$ & $5 / 19(26.3 \%)$ & \\
\hline & $\mathrm{D}(50-70 \%)$ & $3 / 36(8.3 \%)$ & $2 / 17(11.8 \%)$ & $1 / 19(5.3 \%)$ & \\
\hline & $E(>70 \%)$ & $5 / 36(13.8 \%)$ & $3 / 17(17.6 \%)$ & $2 / 19(10.5 \%)$ & \\
\hline \multirow{7}{*}{ Radiological properties, n/N (\%) } & Peripheral ground glass & $36 / 36(100 \%)$ & $17 / 17(100 \%)$ & $19 / 19(100 \%)$ & NA \\
\hline & Alveolar consolidation & $13 / 36(36.1 \%)$ & $8 / 17(47.1 \%)$ & $5 / 19(26.3 \%)$ & 0.196 \\
\hline & Crazy paving pattern & $6 / 36(16.7 \%)$ & 0 & $6 / 19(31.6 \%)$ & $0.020 *$ \\
\hline & Halo sign & 0 & 0 & 0 & NA \\
\hline & Reverse halo sign & $1 / 36(2.8 \%)$ & $1 / 17(5.9 \%)$ & 0 & 0.472 \\
\hline & Wedge-shaped & $1 / 36(2.8 \%)$ & 0 & $1 / 19(5.3 \%)$ & 0.99 \\
\hline & Per-bronchial infiltration & $13 / 36(36.1 \%)$ & $7 / 17(41.2 \%)$ & $6 / 19(31.6 \%)$ & 0.549 \\
\hline
\end{tabular}

SO2, Oxygen saturation; NA, Not available; ${ }^{\star} P$-value $<0.05$.

Table 3. Primary outcomes in Tocilizumab and standard care group.

\begin{tabular}{|c|c|c|c|}
\hline Characteristic & $\begin{array}{l}\text { Tocilizumab } \\
(\mathrm{N}=17)\end{array}$ & $\begin{array}{l}\text { Standard care } \\
(\mathrm{N}=19)\end{array}$ & $P$-value \\
\hline Time to the event (discharge or death), day & $12.88 \pm 9.05$ & $12.05 \pm 8.92$ & 0.784 \\
\hline Time to improvement, day & $9.42 \pm 3.55$ & $9.73 \pm 6.05$ & 0.874 \\
\hline The outcome, n/N (\%) & & & 0.563 \\
\hline Recover & $12 / 17(70.6 \%)$ & 15/19 (78.9\%) & \\
\hline Death & $5 / 17(29.4 \%)$ & $4 / 19(21.1 \%)$ & \\
\hline
\end{tabular}

$\star P$-value $<0.05$

Table 4. Clinical characteristics of patients before and after treatment measurements in each of groups. 


\begin{tabular}{|c|c|c|c|c|c|c|}
\hline \multirow[t]{3}{*}{ Characteristic } & \multicolumn{2}{|l|}{ Before treatment } & \multicolumn{4}{|c|}{ After treatment (Day 3-5) } \\
\hline & Tocilizumab & Standard care & Tocilizumab & \multirow[t]{2}{*}{$P$-value } & Standard care & \multirow[t]{2}{*}{$P$-value } \\
\hline & Mean \pm SD & Mean \pm SD & Mean \pm SD & & Mean \pm SD & \\
\hline SO2 percent & $84.8 \pm 8.21$ & $84.4 \pm 9.73$ & $89.06 \pm 6.89$ & $0.001^{\star}$ & $88.0 \pm 10.05$ & $0.002^{*}$ \\
\hline Systolic blood pressure, mm Hg & $122.76 \pm 24.77$ & $132.21 \pm 24.92$ & $121.4 \pm 10.66$ & 0.415 & $129.4 \pm 18.46$ & 0.526 \\
\hline Diastolic blood pressure, $\mathrm{mm} \mathrm{Hg}$ & $68.81 \pm 17.37$ & $78.47 \pm 14.95$ & $72.0 \pm 8.96$ & 0.734 & $77.0 \pm 12.45$ & 0.668 \\
\hline Heart rate, beats/ min & $90.76 \pm 14.92$ & $93.0 \pm 14.28$ & $80.5 \pm 24.32$ & 0.077 & $88.47 \pm 15.06$ & 0.056 \\
\hline Respiratory rate, breaths/min & $21.76 \pm 3.81$ & $18.89 \pm 2.60$ & $20.43 \pm 4.56$ & 0.211 & $18.15 \pm 1.92$ & 0.125 \\
\hline \multirow[t]{2}{*}{ Body temperature ${ }^{\circ} \mathrm{C}$} & $37.02 \pm 1.50$ & $37.51 \pm 0.73$ & $36.8 \pm 0.42$ & 0.547 & $37.04 \pm 0.32$ & 0.007 \\
\hline & $\mathrm{n} / \mathrm{N}(\%)$ & $\mathrm{n} / \mathrm{N}(\%)$ & $\mathrm{n} / \mathrm{N}(\%)$ & $P$-value & $\mathrm{n} / \mathrm{N}(\%)$ & $P$-value \\
\hline Dyspnea & 15/17 (88.23) & $16 / 19(84.2)$ & 6/16 (37.5) & $0.012^{*}$ & $10 / 19(52.6)$ & $0.031^{*}$ \\
\hline GI Symptom & $5 / 17(29.4)$ & $7 / 19$ (36.8) & $2 / 16(12.5)$ & 0.25 & $1 / 19(5.3)$ & $0.031^{\star}$ \\
\hline Myalgia & $5 / 17(29.4)$ & $10 / 19(52.6)$ & $1 / 16(6.3)$ & 0.125 & 3/19 (15.8) & $0.016 *$ \\
\hline Chest pain & 3/17 (17.6) & 2/19 (10.5) & 0 & 0.25 & 0 & 0.50 \\
\hline Cough & 9/17 (52.9) & $12 / 19(63.1)$ & $4 / 16(25)$ & 0.063 & 6/19 (31.6) & $0.031^{\star}$ \\
\hline Weakness & 14/17 (82.4) & $17 / 19(89.5)$ & 13/16 (81.3) & 0.99 & $13 / 19(68.4)$ & 0.125 \\
\hline Need on Oxygen therapy & $17 / 17(100)$ & $19 / 19(100)$ & $14 / 17(76.4)$ & 0.103 & $17 / 19(89.4)$ & 0.486 \\
\hline
\end{tabular}

${ }^{*} P$-value $<0.05, P$-value was calculated based on the after treatment and before treatment measurements in each of studied groups, SO2, $0 x y g e n$ saturation; mm Hg, Millimeter of mercury; min, Minute; ${ }^{\circ} \mathrm{C}$, Centigrade; GI, Gastrointestinal; NA, Not available.

Table 5. Laboratory findings of patients before and after treatment in each of groups. 


\begin{tabular}{|c|c|c|c|c|c|c|c|c|c|c|c|}
\hline \multicolumn{2}{|c|}{ Characteristic } & \multicolumn{2}{|c|}{ Before treatment } & \multicolumn{4}{|c|}{ After treatment (Day 3-5) } & \multicolumn{4}{|c|}{ After treatment (Discharge or death) } \\
\hline & & \multirow{3}{*}{$\begin{array}{l}\text { Tocilizumab } \\
\text { Mean } \pm \text { SD }\end{array}$} & \multirow{3}{*}{$\begin{array}{l}\begin{array}{l}\text { Standard } \\
\text { care }\end{array} \\
\text { Mean } \pm \\
\text { SD }\end{array}$} & \multirow{3}{*}{$\begin{array}{l}\text { Tocilizumab } \\
\text { Mean } \\
\text { SD }\end{array}$} & \multirow[t]{3}{*}{$\begin{array}{l}P \\
\text { value }\end{array}$} & \multirow{3}{*}{$\begin{array}{l}\text { Standard } \\
\text { care } \\
\text { Mean } \pm \\
\text { SD }\end{array}$} & \multirow[t]{3}{*}{$\begin{array}{l}P \\
\text { value }\end{array}$} & Tocilizumab & \multirow[t]{3}{*}{$\begin{array}{l}P \\
\text { value }\end{array}$} & \multirow{3}{*}{$\begin{array}{l}\begin{array}{l}\text { Standard } \\
\text { care }\end{array} \\
\text { Mean } \pm \\
\text { SD }\end{array}$} & \multirow[t]{3}{*}{$\begin{array}{l}P \\
\text { value }\end{array}$} \\
\hline & & & & & & & & Mean SD & & & \\
\hline & & & & & & & & & & & \\
\hline \multicolumn{2}{|c|}{ ALT (U/L) } & $\begin{array}{l}50.92 \pm \\
34.47\end{array}$ & $\begin{array}{l}27.33 \pm \\
9.64\end{array}$ & $\begin{array}{l}57.85 \pm \\
34.08\end{array}$ & 0.686 & - & NA & $\begin{array}{l}61.6 \pm \\
31.98\end{array}$ & 0.893 & - & NA \\
\hline \multicolumn{2}{|c|}{ AST (U/L) } & $\begin{array}{l}52.64 \pm \\
21.13\end{array}$ & $\begin{array}{l}44.05 \pm \\
14.71\end{array}$ & $\begin{array}{l}47.14 \pm \\
12.30\end{array}$ & $0.042^{\star}$ & - & NA & $48 \pm 19.83$ & 0.50 & - & NA \\
\hline \multicolumn{2}{|c|}{ CPK (U/L) } & $\begin{array}{l}148.3 \pm \\
89.9\end{array}$ & $\begin{array}{l}167.5 \pm \\
195.4\end{array}$ & $130 \pm 142.8$ & 0.655 & - & NA & - & NA & - & NA \\
\hline \multicolumn{2}{|c|}{ FBS mg/dL } & $139 \pm 53.47$ & $\begin{array}{l}132.1 \pm \\
54.31\end{array}$ & $\begin{array}{l}166.6 \pm \\
62.82\end{array}$ & 0.686 & - & NA & - & NA & - & NA \\
\hline \multicolumn{2}{|c|}{ CRP (mg/L) } & $\begin{array}{l}71.8 \pm \\
49.45\end{array}$ & $\begin{array}{l}64.58 \pm \\
31.98\end{array}$ & $\begin{array}{l}46.5 \pm \\
48.09\end{array}$ & 0.155 & $\begin{array}{l}40.38 \pm \\
38.86\end{array}$ & 0.075 & $\begin{array}{l}33.75 \pm \\
27.18\end{array}$ & 0.068 & $\begin{array}{l}40.66 \pm \\
38.18\end{array}$ & 0.075 \\
\hline \multicolumn{2}{|c|}{$\mathrm{ESR}(\mathrm{mm} / \mathrm{hr})$} & $\begin{array}{l}42.9 \pm \\
28.06\end{array}$ & $\begin{array}{l}68.3 \pm \\
33.9\end{array}$ & $66.2 \pm 50.0$ & 0.273 & $\begin{array}{l}61.14 \pm \\
31.06\end{array}$ & 0.753 & $\begin{array}{l}41.5 \pm \\
10.60\end{array}$ & 0.317 & $\begin{array}{l}32.5 \pm \\
10.6\end{array}$ & 0.317 \\
\hline \multicolumn{2}{|c|}{ Ferritin (ng/mL) } & $\begin{array}{l}601.8 \pm \\
653.7\end{array}$ & $\begin{array}{l}433.3 \pm \\
250.7\end{array}$ & $\begin{array}{l}1026 \pm \\
1217\end{array}$ & 0.207 & $\begin{array}{l}762.4 \pm \\
720\end{array}$ & 0.136 & $581 \pm 226.4$ & 0.066 & $\begin{array}{l}553.6 \pm \\
283.6\end{array}$ & 0.715 \\
\hline \multicolumn{2}{|c|}{ IL-6 (pg/ml) } & $\begin{array}{l}622.9 \pm \\
741.9\end{array}$ & $\begin{array}{l}271.3 \pm \\
440.6\end{array}$ & $\begin{array}{l}251.1 \pm \\
163.2\end{array}$ & 0.198 & $\begin{array}{l}90.5 \pm \\
75.87\end{array}$ & 0.062 & $\begin{array}{l}220.2 \pm \\
95.03\end{array}$ & 0.893 & $\begin{array}{l}121.7 \pm \\
96.11\end{array}$ & 0.99 \\
\hline \multicolumn{2}{|c|}{$\begin{array}{l}\text { D-Dimer } \\
\text { ( } \mu \mathrm{g} / \mathrm{mL})\end{array}$} & $0.69 \pm 0.29$ & $\begin{array}{l}1.05 \pm \\
1.25\end{array}$ & $1.43 \pm 1.42$ & 0.345 & $\begin{array}{l}0.72 \pm \\
0.49\end{array}$ & 0.735 & $1.85 \pm 1.62$ & 0.655 & $\begin{array}{l}0.95 \pm \\
0.64\end{array}$ & 0.99 \\
\hline \multicolumn{2}{|c|}{ Troponin } & $31.7 \pm 79.7$ & $\begin{array}{l}15.20 \pm \\
18.87\end{array}$ & $\begin{array}{l}60.2 \pm \\
43.32\end{array}$ & 0.514 & $\begin{array}{l}25.2 \pm \\
14.84\end{array}$ & 0.929 & $\begin{array}{l}118.8 \pm \\
113.3\end{array}$ & 0.99 & $\begin{array}{l}65.1 \pm \\
45.1\end{array}$ & 0.99 \\
\hline \multicolumn{2}{|c|}{$\begin{array}{l}\text { WBC } \\
\text { count/MCL }\end{array}$} & $\begin{array}{l}7668 \pm \\
2808\end{array}$ & $\begin{array}{l}6428 \pm \\
2539\end{array}$ & $\begin{array}{l}10574 \pm \\
8758\end{array}$ & 0.125 & $\begin{array}{l}7716 \pm \\
3882\end{array}$ & 0.396 & $\begin{array}{l}8990 \pm \\
5297\end{array}$ & 0.99 & $\begin{array}{l}6984.6 \pm \\
2530.3\end{array}$ & 0.807 \\
\hline \multicolumn{2}{|c|}{ RBC percent } & $4.43 \pm 1.21$ & $\begin{array}{l}4.42 \pm \\
0.64\end{array}$ & $4.61 \pm 0.88$ & 0.887 & $\begin{array}{l}4.20 \pm \\
4.15\end{array}$ & 0.067 & $4.58 \pm 1.16$ & 0.833 & $\begin{array}{l}4.11 \pm \\
0.80\end{array}$ & 0.152 \\
\hline \multicolumn{2}{|c|}{$\begin{array}{l}\text { Platelet count } \\
(\times 1000 / \mathrm{MCL})\end{array}$} & $\begin{array}{l}196.62 \pm \\
70.72\end{array}$ & $\begin{array}{l}204.63 \pm \\
72.24\end{array}$ & $\begin{array}{l}233.68 \pm \\
85.61\end{array}$ & 0.191 & $\begin{array}{l}234.15 \pm \\
104.19\end{array}$ & 0.184 & $\begin{array}{l}248.0 \pm \\
88.41\end{array}$ & 0.263 & $\begin{array}{l}270.23 \pm \\
97.82\end{array}$ & 0.075 \\
\hline \multicolumn{2}{|c|}{$\begin{array}{l}\text { Hemoglobin } \\
(\mathrm{gm} / \mathrm{dl})\end{array}$} & $\begin{array}{l}11.89 \pm \\
3.13\end{array}$ & $\begin{array}{l}12.78 \pm \\
1.66\end{array}$ & $12.5 \pm 2.18$ & 0.807 & $\begin{array}{l}11.78 \pm \\
1.50\end{array}$ & $0.002^{*}$ & $\begin{array}{l}12.04 \pm \\
2.65\end{array}$ & 0.944 & $\begin{array}{l}11.59 \pm \\
1.56\end{array}$ & $0.025^{*}$ \\
\hline \multicolumn{2}{|c|}{$\begin{array}{l}\text { Hematocrit } \\
\text { Percent }\end{array}$} & $\begin{array}{l}35.44 \pm \\
7.26\end{array}$ & $\begin{array}{l}37.39 \pm \\
5.30\end{array}$ & $38.6 \pm 5.10$ & 0.245 & $\begin{array}{l}34.36 \pm \\
3.73\end{array}$ & 0.099 & $\begin{array}{l}36.45 \pm \\
7.59\end{array}$ & 0.575 & $\begin{array}{l}33.03 \pm \\
3.13\end{array}$ & 0.017 * \\
\hline \multicolumn{2}{|c|}{$\begin{array}{l}\text { Neutrophil } \\
\text { Percent }\end{array}$} & $\begin{array}{l}75.85 \pm \\
9.98\end{array}$ & $\begin{array}{l}76.27 \pm \\
8.90\end{array}$ & $\begin{array}{l}74.93 \pm \\
14.10\end{array}$ & 0.814 & $\begin{array}{l}80.66 \pm \\
9.56\end{array}$ & 0.477 & $\begin{array}{l}66.85 \pm \\
14.26\end{array}$ & $0.042^{\star}$ & $\begin{array}{l}80.71 \pm \\
7.02\end{array}$ & 0.397 \\
\hline \multicolumn{2}{|c|}{$\begin{array}{l}\text { Lymphocyte } \\
\text { count/ MCL }\end{array}$} & $\begin{array}{l}1212 \pm \\
634.3\end{array}$ & $\begin{array}{l}910.3 \pm \\
421.4\end{array}$ & $\begin{array}{l}1385 \pm \\
687.1\end{array}$ & 0.917 & $\begin{array}{l}891.5 \pm \\
446.9\end{array}$ & 0.878 & $\begin{array}{l}1530.3 \pm \\
719.5\end{array}$ & 0.225 & $\begin{array}{l}887.8 \pm \\
425.5\end{array}$ & 0.99 \\
\hline Mono & yte count & $\begin{array}{l}395.8 \pm \\
281.9\end{array}$ & $\begin{array}{l}359.4 \pm \\
116.5\end{array}$ & $\begin{array}{l}571.2 \pm \\
500.6\end{array}$ & 0.182 & $\begin{array}{l}331.9 \pm \\
208.1\end{array}$ & 0.917 & $\begin{array}{l}452.1 \pm \\
132.4\end{array}$ & 0.686 & $\begin{array}{l}389.6 \pm \\
220.1\end{array}$ & 0.686 \\
\hline VBG & $\mathrm{PH}$ & $7.36 \pm 0.15$ & $\begin{array}{l}7.40 \pm \\
0.047\end{array}$ & $7.32 \pm 0.14$ & 0.213 & $\begin{array}{l}7.40 \pm \\
0.059\end{array}$ & 0.842 & $\begin{array}{l}7.41 \pm \\
0.047\end{array}$ & 0.173 & $\begin{array}{l}7.39 \pm \\
0.03\end{array}$ & 0.238 \\
\hline & $\begin{array}{l}\mathrm{HCO} 3 \\
\text { (meq/L) }\end{array}$ & $\begin{array}{l}23.20 \pm \\
24.20\end{array}$ & $\begin{array}{l}26.10 \pm \\
4.56\end{array}$ & $\begin{array}{l}26.34 \pm \\
6.89\end{array}$ & 0.328 & $\begin{array}{l}25.98 \pm \\
3.94\end{array}$ & 0.955 & $\begin{array}{l}26.34 \pm \\
11.97\end{array}$ & 0.345 & $\begin{array}{l}28.02 \pm \\
3.71\end{array}$ & 0.388 \\
\hline & $\begin{array}{l}\text { PCO2 } \\
(\mathrm{mmHg})\end{array}$ & $\begin{array}{l}40.06 \pm \\
7.60\end{array}$ & $\begin{array}{l}41.88 \pm \\
9.78\end{array}$ & $\begin{array}{l}49.8 \pm \\
13.72\end{array}$ & 0.099 & $\begin{array}{l}42.23 \pm \\
7.98\end{array}$ & 0.776 & $\begin{array}{l}46.57 \pm \\
9.50\end{array}$ & 0.750 & $\begin{array}{l}43.95 \pm \\
8.02\end{array}$ & 0.463 \\
\hline
\end{tabular}

${ }^{*} P$-value $<0.05, P$-value was calculated based on the after treatment measurements compared with before measurement (as a reference) in each of studied groups, ALT: Alanine aminotransferase; AST: Aspartate aminotransferase; CPK: Creatine phosphokinase; CRP: C-reactive protein; ESR: erythrocyte sedimentation rate; FBS: Fasting blood sugar; gm/dl: Grams per deciliter; HCO3: Bicarbonate; LDH: Lactic acid dehydrogenase; MCL: 
Microliter; mg/L Milligrams per liter; meq/L: Milliequivalent per liter; mm Hg: Millimeter of mercury; mm/hr: Millimeters per hour; ng/ml: Nanogram per milliliter; PCO2: Partial pressure of carbon dioxide; pg/ml: Pictogram per milliliter; RBC: Red blood cell; SD, Standard deviation; U/L: Unit per liter; VBG: Venous blood gas; WBC: White blood cell; NA: Not available.

\section{Figures}

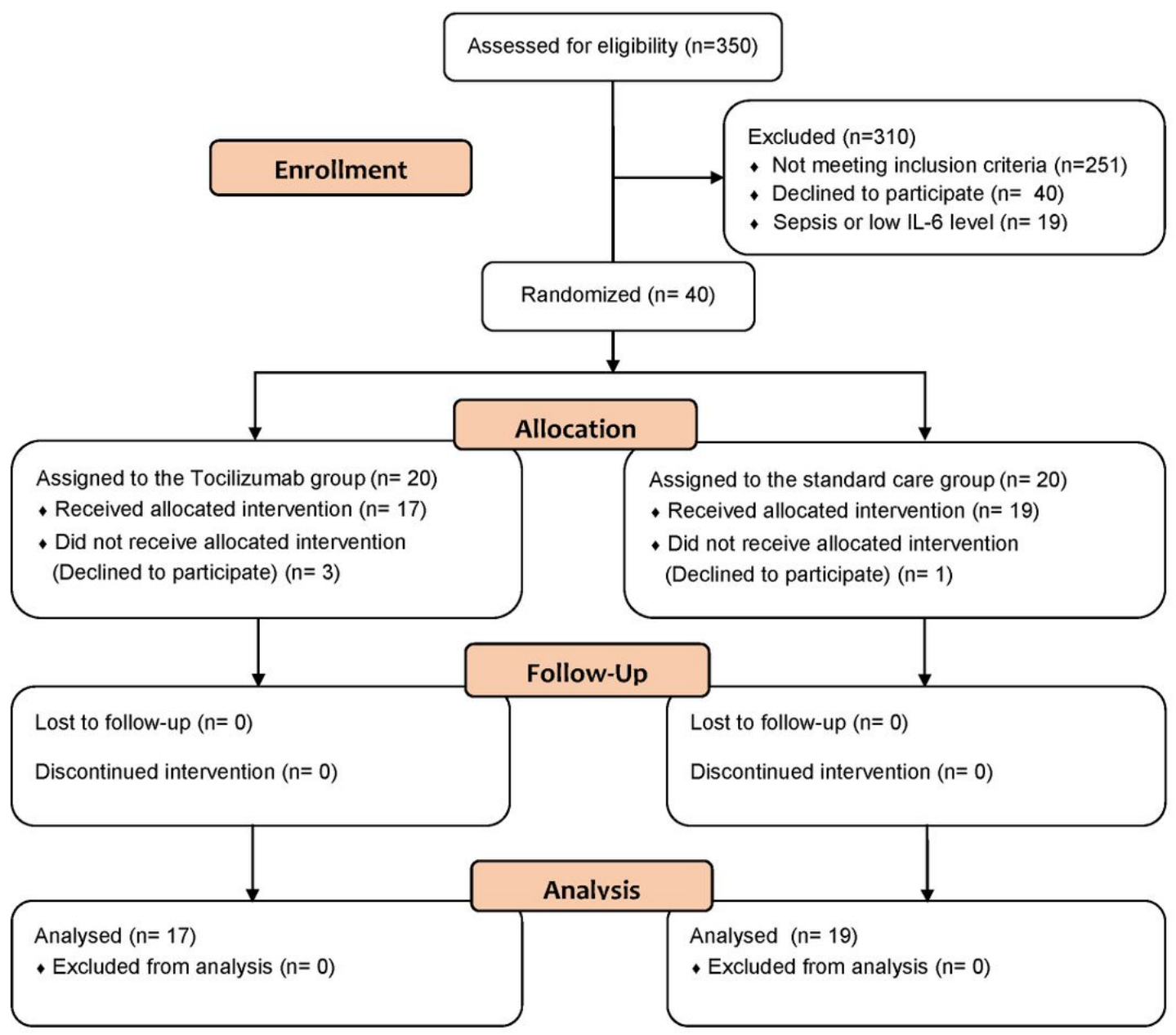

\section{Figure 1}

Randomization, enrollment, and treatment assignment. 


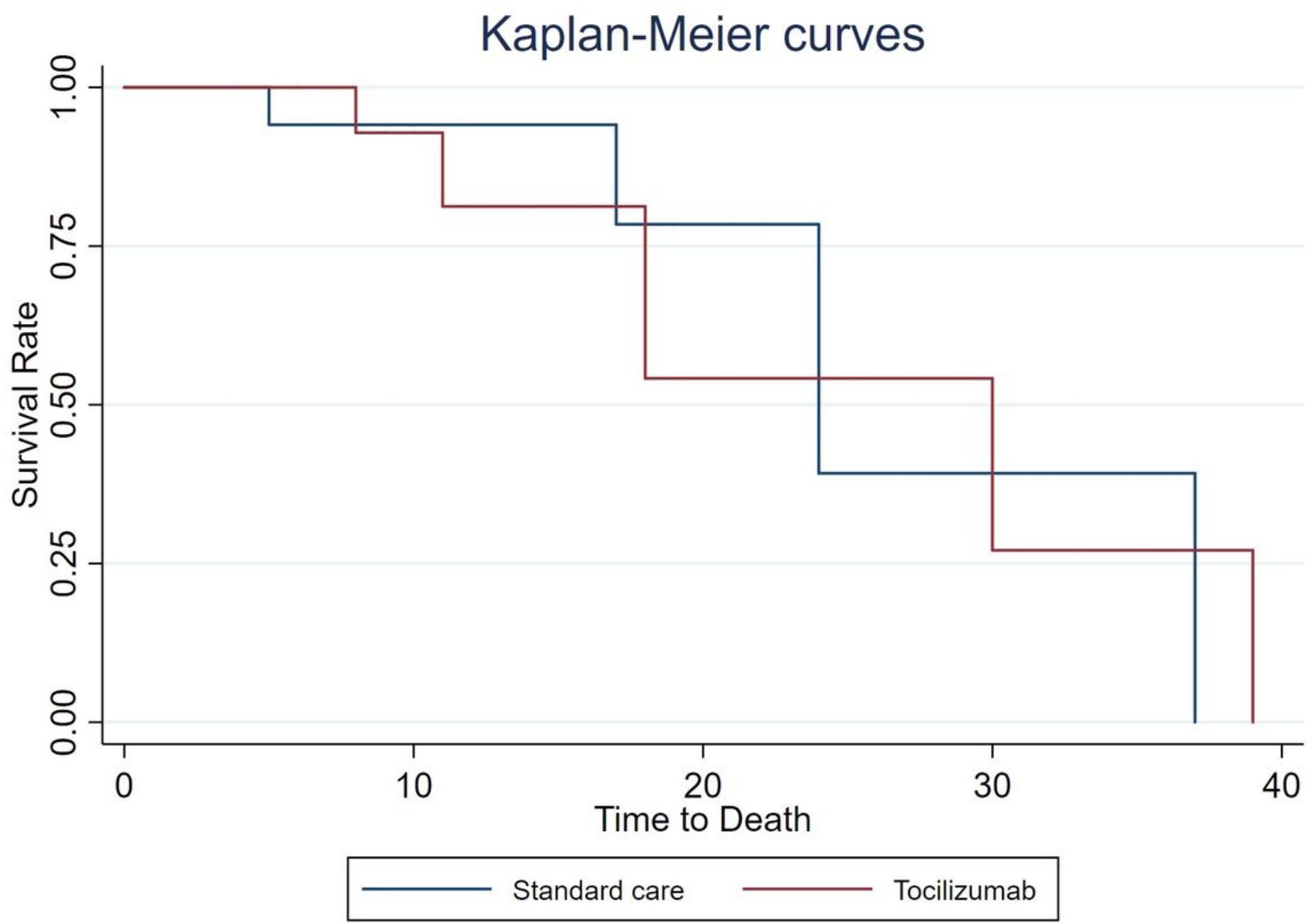

Figure 2

Kaplan-Meier curves for statistical comparison of time to death between both groups (P-value=0.973).

\section{Supplementary Files}

This is a list of supplementary files associated with this preprint. Click to download.

- CONSORT2010Checklist.doc

- SupplementaryFigure1.pdf

- SupplementaryTable1.pdf 